\title{
Féeries
}

Études sur le conte merveilleuX, XVII ${ }^{e}$ XIXe siècle

Le dialogisme intertextuel des contes des Grimm

\section{Ruth B. Bottigheimer (éd.), Fairy Tales Framed, Early Forewords, Afterwords, and Critical Words}

Suny Press, Albany (États-Unis), 2012

\section{Jean-François Perrin}

\section{OpenEdition}

\section{Journals}

Édition électronique

URL : http://journals.openedition.org/feeries/848

DOI : $10.4000 /$ feeries. 848

ISSN : 1957-7753

Éditeur

UGA Éditions/Université Grenoble Alpes

Édition imprimée

Date de publication : 15 octobre 2012

Pagination : 299-303

ISBN : 978-2-84310-233-2

ISSN : 1766-2842

\section{Référence électronique}

Jean-François Perrin, «Ruth B. Bottigheimer (éd.), Fairy Tales Framed, Early Forewords, Afterwords, and

Critical Words », Féeries [En ligne], 9 | 2012, mis en ligne le 15 octobre 2012, consulté le 24 septembre 2020. URL : http://journals.openedition.org/feeries/848; DOI : https://doi.org/10.4000/feeries.848

\section{(c) Féeries}


saient comme leur poche. Le Sultan de Poe n'est pas le premier à croire aux histoires pour les avoir déjà lues ou entendues : après Don Quichotte, le sultan du Sopha (Crébillon) est exactement dans ce cas. La perspective est ainsi faussée alors qu'il suffisait de se mettre au courant : les œuvres de Crébillon sont en effet disponibles chez Garnier Flammarion, et leur édition savante récente ainsi que celle des contes d'Hamilton sont publiées chez Champion ("Bibliothèque des Génies et des Fées», 2008 et 20IO).

Que conclure? On peut se demander s'il est réellement utile de rééditer des nouvelles de Gautier et de Poe aujourd'hui accessibles dans d'excellentes éditions de poche bien annotées ou en éditions critiques; à cet égard É. Stead n'apporte qu'assez peu, quoique, bien sûr, les illustrations drolatiques d'A. Gill et la notice le concernant valent un détour curieux.

Heureusement tout de même, Davidescu et sa nouvelle constitueront une précieuse découverte pour les lecteurs de cette anthologie : l'écrivain roumain (I886-I954), dont la redécouverte est toute récente, est essayiste (lié au symbolisme), romancier et poète; une vie assez malheureuse, une position "nationaliste" politiquement suicidaire en 1947, l'incarcération en 1949 jusqu'à la mort ont failli effacer son œuvre. Dans sa très originale Mille et deuxième nuit, Dinarzade partage le rôle de la conteuse, endossant en outre ici une figure d'analyste réfléchissant sur les lois générales de la création à partir d'une comparaison (joueuse et paradoxale) de la structure du Corbeau de Poe et de deux histoires des Nuits relatives à l'amour impossible.

Ce qui sauve l'ensemble.

Jean-François Perrin

Ruth B. Bottigheimer (éd.), Fairy Tales Framed, Early Forewords, Afterwords, and Critical Words, Suny Press, Albany (États-Unis), 20I2, 254 p.

Les lecteurs de Féeries savent que Ruth B. Bottigheimer défend de façon tranchée une thèse "littérariste» sur l'origine et la propagation européenne du conte de fées, en considérant que la thèse de sa diffusion orale est un mythe dont elle traque avec détermination la progressive construction par les lettrés eux-mêmes, plus ou moins à leur insu ${ }^{\mathrm{I2}}$.

I2. Voir en particulier son Fairy Godfather: Straparola, Venice and the Fairy Tale Tradition, Philadelphie, University of Pennsylvania Press, 2002. On peut lire son article «Les contes médiévaux et les contes de fées modernes", dans Féeries, ${ }^{\circ}{ }^{7}$, Grenoble, Ellug, 20IO, p. 2I-44 (désormais en ligne). 
Ce nouvel ouvrage qu'elle a conçu avec cinq autres chercheuses - Suzanne Magnanini, Nancy Canepa, Betsey Harries, Christine Jones et Sophie Reynard - est centré sur l'étude des questions d'encadrement et de paratextualité. L'enjeu général étant d'analyser comment les dispositifs conversationnels que figurent toujours les récits-cadres issus de Boccace instituent une topique littéraire de la fiction d'oralité, et comment les préfaces et autres dédicaces de l'auteur ou des éditeurs situent le conte merveilleux dans le champ littéraire où il entre en concurrence avec d'autres genres, depuis Boccace dans le domaine italien et depuis $\mathrm{M}^{\mathrm{me}} \mathrm{d}$ 'Aulnoy et Perrault dans le domaine français.

Après une Introduction de R. B. Bottigheimer, le volume se divise en deux grandes parties : «Le conte de fées en Italie : premiers auteurs, théoriciens et critiques"; "Le conte de fées en France : établir le canon». Chacune de ces parties comporte une présentation de la matière dans chaque pays, suivie d'une série de paratextes critiques ou narratifs. Chacun de ces textes (traduits en anglais) bénéficie d'une précise introduction permettant de situer son contexte et ses enjeux.

La partie la plus neuve pour le lecteur français est celle qui est consacrée au conte de fées littéraire en Italie. Elle est principalement réalisée par S. Magnanini qui en fait véritablement découvrir l'histoire.

En termes de corpus d'abord. Nous savions bien que Les Nuits facétieuses de Straparola comportaient, outre des imitations du Décaméron, une série de contes merveilleux, et que Le Conte des contes de Basile avait pu circuler, au moins partiellement, jusque sous la plume de Perrault et de ses consœurs en féerie. S. Magnanini avait d'ailleurs montré en 2007, dans un article publié par Marvels \& Tales, le rôle joué à cet égard par le libraire napolitain Antonio Bulifon ${ }^{13}$. Or il faut ajouter à ces pères fondateurs les noms de trois émules : Lorenzo Selva qui inclut trois contes de fées dans son roman Les Métamorphoses ou la transformation d'un homme vertueux $(\mathrm{I} 582)^{\mathrm{I}}$, Lorenzo Lippi qui inclut trois contes de Basile dans son épopée burlesque Malmantile reconquis (I676), Pompeo Sarnelli qui publie en I684 cinq contes en dialecte napolitain, Il Posilecheata. Comme chez Basile, ces contes sont écrits en dialecte.

13. S. Magnanini, «Postulated Routes from Naples to Paris: Antonio Bulifon and the Italian Literary Fairy Tale in France", Marvels and Tales, vol. 2I, n' 2, 2007, p. 78-92.

I4. Pour plus d'informations, je prie qu'on se reporte à mon compte rendu, dans la présente livraison, de la traduction de ces contes par S. Magnanini dans Marvels \& Tales, vol. 23, nº 2, 20II, p. 331-370. 
Si l'on voulait résumer l'enjeu de la démonstration conduite ici, c'est que jamais, en Italie, la question du conte merveilleux ne fut posée indépendamment d'une réflexion lettrée sur l'esthétique des genres littéraires. Après avoir rappelé le rôle central joué en arrière-plan par le Décaméron et son récit-cadre comme modèle topique pour tout ce qui suivra, dans la nouvelle jusqu'à Bandello aussi bien que dans le conte merveilleux italien, S. Magnanini insiste sur le rôle qu'a joué, sur le plan de l'esthétique des genres littéraires, la Généalogie des dieux païens (1335) de Boccace qui resta longtemps l'ouvrage de référence en Europe pour ce qui concerne la mythologie antique. Le chapitre XIv, 9 de l'ouvrage, "Qu'écrire une fiction est plus utile que nuisible» (ici traduit et présenté par R. B. Bottigheimer), pose en effet que les récits dénués de vraisemblance comme les contes merveilleux ne présentent d'intérêt que pour un public inculte ou enfantin et ne sont pas dignes de la plume d'un lettré. En revanche, le merveilleux des favole des maitres classiques comme celui répandu dans la poésie épique n’a pas ce statut déplorable chez les lettrés, car il est a priori susceptible d'une interprétation allégorique; or si cette allégorisation sera, chez Perrault, dans la préface de Grisélidis nouvelle, Avec le Conte de Peau d'Ane, et celui des Souhaits ridicules ( ${ }^{\mathrm{e}}$ éd., I695) et dans les moralités des Histoires ou contes du temps passé, un des éléments de sa stratégie pour crédibiliser le genre dans le champ littéraire, elle l'est déjà, en registre chrétien, dans les trois contes insérés par L. Selva dans son roman de $1582^{15}$, et encore dans l'édition du Conte des contes en I679 par Bartolomeo Lupardi, dont la Lettre-dédicace renvoie à l'image classique du verre de médecine amère qu'un peu de sucre rend supportable aux enfants, pour affirmer que les contes de Basile ont une portée didactique voilée. Pour autant, les défenseurs du genre ne firent pas recette au pays du Tasse et de L'Arioste et son image reste identifiée au public des illettrés. Les spécialistes du XvirI ${ }^{\mathrm{e}}$ siècle qui se procureront

15. Lorenzo Selva est le pseudonyme littéraire d'un frère prêcheur franciscain impliqué dans la réforme catholique issue du concile de Trente, proche de Grégoire XIII et auteur de divers commentaires sur la Bible. La trame de son roman transpose en mode chrétien celle de L'Âne d'or (déjà utilisé par Boccace dans le Décaméron et très présent dans la culture italienne de la Renaissance, que ce soit par la traduction de Boiardo ou la diffusion autonome de la fable de Psyché, y compris sur le plan iconographique) : dans ses Métamorphoses, un jeune homme transformé en serpent à la suite d'un sort parcourt les campagnes à la recherche de sa bien-aimée dont une goutte de sang lui rendra forme humaine; encore faudra-t-il, pour qu'elle l'épouse, qu'il reconnaisse les péchés qui ont causé sa métamorphose et place l'amour céleste au-dessus de l'amour terrestre. Plusieurs fois réédité en Italie, ce roman a été traduit en français en I6II par J. Baudoin. Ces données sont tirées de la remarquable introduction de $S$. Magnanini à la traduction anglaise qu'elle donne de ces trois contes dans son étude : "Between Straparola and Basile. Three Fairy Tales from Lorenzo Selva's Della métamorfosi (1582)", Marvels and Tales, vol. 25, $\mathrm{n}^{\circ}$ 2, 20II, p. 3II-369. Je renvoie à mon compte rendu dans ce numéro. 
cette anthologie découvriront d'ailleurs le mal que pensait l'abbé Galliani du recueil de Basile dont le baroquisme le dégoûte autant que l'état de dégénérescence du dialecte napolitain dont il témoigne, par comparaison à ce que fut son âge d'or littéraire au XIII ${ }^{\mathrm{e}}$ siècle.

Les textes du XVIII ${ }^{\mathrm{e}}$ siècle italien procurés par cette anthologie montrent en effet que le débat sur ce genre est aussi déterminé par l'appréciation esthétique de l'intérêt littéraire de l'usage des dialectes. Basile écrit en napolitain, et son recueil est traduit en bolognais en $\mathrm{1742}$, sous le titre La chiaqlira dla banzola (Les Potins du banc) — les éditrices présentant le recueil comme écrit par des femmes pour désennuyer les femmes, avec une gravure en page de titre liant clairement le genre à la sphère domestique. Ainsi se transmet, en Italie autant qu'en France et sans doute dans l'Europe entière, l'inusable légende du conte de bonne femme alias "conte populaire». Il reste que lorsque Carlo Gozzi remit en selle la commedia dell'arte avec l'extraordinaire succès de L'amore delle tre melarence (L'amour des trois oranges) en $\mathrm{I76}$ I, son frère Gasparo s'empressa de défendre la portée allégorique de cette favola.

Les textes du débat français cités dans la première partie de cette anthologie sont bien connus des spécialistes : paratextes de Perrault; ceux de $\mathrm{M}^{\text {lle }}$ L'Héritier dans ses Euvres mêlées; les deux contes insérés par Catherine Bernard dans Inès de Cordoue, deux extraits du Mercure Galant concernant Perrault et un extrait de l'Histoire de la marquise/marquis de Banneville (Choisy); la dédicace à Madame et le Conte de Saint-Cloud de $\mathrm{M}^{\mathrm{me}} \mathrm{d}^{\prime}$ Aulnoy, ainsi que les abrégés de ses romans-cadres; une petite notice de $\mathrm{M}^{\text {lle }}$ de La Force à son Conte des contes; la dédicace aux «Fées modernes» et la notice de 1699 de $\mathrm{M}^{\mathrm{me}}$ de Murat; la Conversation sur les contes de fées de l'abbé de Villiers; la dédicace et les avertissements de Galland.

L'introduction de R. B. Bottigheimer développe une fine et méthodique réflexion portant sur la terminologie générique flottante qui caractérise en France l'émergence de cet intrus dans le paysage générique. J'y ajouterai qu'au XVIII ${ }^{\mathrm{e}}$ siècle, le corpus des contes de fées et des contes orientaux finit par se ranger dans la rubrique "Conte de fées et autres contes merveilleux», à l'article XI de la Bibliothèque des romans (1734) de Lenglet-Dufresnoy. Les notices (principalement de R. B. Bottigheimer) présentent surtout les éléments contextuels nécessaires à l'intelligence des textes présentés. Si ceux-ci sont désormais bien accessibles et très étudiés de notre côté de l'Atlantique grâce, notamment, à la monumentale anthologie critique de la «Bibliothèque des Génies et des Fées» chez Champion ${ }^{16}$, cet ouvrage

I6. Voir en particulier la présentation par J. Boch des grands textes du débat français sur le conte à la fin du XVII ${ }^{\mathrm{e}}$ siècle, dans L'Âge d'or du conte des fées, Paris, Champion, coll. «Bibliothèque des Génies et des Fées" n 5, 2007, p. 327-352. 
va permettre au chercheur anglophone d'accéder désormais plus aisément que par le passé à ce corpus paratextuel du conte merveilleux en Italie et en France, et par là aux enjeux esthétiques et idéologiques contrastés dont il est chargé.

Une seule réserve : on regrettera que l'œuvre d'Hamilton (publiée en I730-I73I mais composée entre I700 et I7I7 et dévorée en manuscrits par les contemporains) ne soit pas même mentionnée, alors qu' elle est totalement concernée - et de façon extrêmement originale (le récit-cadre de Galland s'y trouve par exemple génialement déconstruit) — par l'utile réflexion que cette anthologie tente de développer autour de l'encadrement narratif et des problèmes esthétiques qui s'y trouvent liés ${ }^{17}$.

Jean-François Perrin

17. La portée à cet égard de la lettre en vers à M.L.C.D.F., qui ouvre Les Quatre Facardins, n’avait pas échappé à l'attention de l'éditeur du Cabinet des fées qui la cite intégralement. Voir mon édition de ce conte dans Hamilton et autres conteurs, Paris, Champion, coll. "Bibliothèque des Génies et des Fées" n I6, 2008, p. 537-542. 